\title{
Field Evaluation of the Performance of the RTU Challenge Unit: Daikin Rebel
}

March 2015

Prepared for the U.S. Department of Energy By:

W Wang

S Katipamula

$\mathrm{H} \mathrm{Ngo}$

RM Underhill

Pacific Northwest National Laboratory 


\section{Disclaimer}

This document was prepared as an account of work sponsored by the United States Government. While this document is believed to contain correct information, neither the United States Government nor any agency thereof, nor Pacific Northwest National Laboratory, nor any of their employees, makes any warranty, express or implied, or assumes any legal responsibility for the accuracy, completeness, or usefulness of any information, apparatus, product, or process disclosed, or represents that its use would not infringe privately owned rights. Reference herein to any specific commercial product, process, or service by its trade name, trademark, manufacturer, or otherwise, does not constitute or imply its endorsement, recommendation, or favoring by the United States Government or any agency thereof, or Pacific Northwest National Laboratory. The views and opinions of authors expressed herein do not necessarily state or reflect those of the United States Government or any agency thereof or Pacific Northwest National Laboratory.

The work described in this report was funded by the U.S. Department of Energy under Contract No. DE-AC0576RL01830. 


\section{Acknowledgements}

The authors would like to acknowledge the Buildings Technologies Office of the U.S. Department of Energy (DOE) Office of Energy Efficiency and Renewable Energy for supporting the research and development effort. The authors would also like to thank Charles Llenza, Technical Development Manager at DOE; Linda Sandahl (Program Manager at PNNL) for thoughtful comments and insights; Nick Fernandez for the technical review of the report; and Sue Arey for editorial support. We also want to thank Ken Hellewell and Danny Miller from Transformative Wave Technologies of Kent, WA for their help in installing and commissioning the metering and monitoring equipment on the two rooftop units. We also would like to thank Mike Faas and Randy Tremain from Publix for their cooperation and willingness to allow DOE and PNNL to monitor the rooftop units.

For more information contact:

Tech Demo Reports

Mail Stop EE-5B

US Department of Energy

1000 Independence Ave, SW

Washington, DC 20585-0121

techdemo@ee.doe.gov 


\section{Executive Summary}

In 2011, the U.S. Department of Energy's Building Technology Office (DOE's BTO), with help from the Better Buildings Alliance (BBA) members, developed a specification (RTU Challenge) for high performance rooftop airconditioning units (RTUs) with capacity ranges between 10 and 20 tons (DOE 2013). Daikin's Rebel RTU was recognized by DOE in May 2012 as first to meet the RTU Challenge specifications. This report documents the testing of a Rebel unit and a standard reference unit in the field and compares the seasonal efficiency of the two units.

The goal of the RTU Challenge demonstration was to estimate the seasonal performance of the RTU Challenge unit and the annual savings that could be achieved by installing the challenge unit instead of an alternate standard unit. The demonstration took place at two grocery stores located in New Smyrna Beach and Port Orange, Florida. The Rebel unit was installed as a replacement of an existing unit in July 2013 at the New Smyrna Beach store. The reference unit was an existing rooftop unit in the Port Orange store that is about 6 years old. The reference unit had two compressors for staged cooling and a constant-speed supply fan. Both units had the same rated cooling capacity of 7.5 tons and served each store's office spaces with similar footprints.

A set of sensors were used to measure the dry-bulb temperature and the relative humidity for the outdoor-air, the return-air, the mixed-air, and the supply-air. RTU total power consumption was also measured using a power transducer. These sensor measurements, together with a number of control signals were monitored at 1-minute intervals from August 2013 to September 2014.

The average daily energy efficiency ratio (EER) was computed for each unit using the monitored data. The ratio of the average EER for the two units varied between 0.9 and 2.4. The Rebel unit had a higher daily EER than the reference unit for almost all days. The EER ratio increased as the daily average outdoor-air temperature decreased, as expected. This means that RTUs with variable-speed compressors and variable-speed fans, like Rebel, had better part-load efficiencies than units using constant speed supply fans and ON/OFF controls for compressors. The average of the daily EER ratio for all days was approximately 1.38 , which means that on average, the daily EER of the Rebel unit was $38 \%$ higher than that of the reference unit.

In addition to daily EER, the seasonal cooling efficiency was also calculated over the entire monitoring period. Over the 12-month period, the reference unit and the Rebel unit had seasonal EERs of 8.3 and 10.9, respectively. The Rebel unit's seasonal EER was about 31\% higher than the reference unit. This result was slightly lower than the findings from our previous simulation work, which estimated that in hot and humid climates, Rebel would consume about $40 \%$ less electricity than a RTU with a constant-speed supply fan and a single-stage mechanical cooling. Possible reasons for this difference included: 1 ) the load that the two units in the field served were different, while the two units in the simulation served the same load; and 2) the reference unit had higher operating efficiency than the number used in the simulation runs.

The annual energy savings from the rooftop unit replacement with Rebel was about $16,000 \mathrm{kWh}$, which translated to roughly 3.8 years in simple payback. 
It was a challenge to find two units running in two different spaces that had served similar cooling loads. Although two grocery stores with similar layouts were selected, the monitored data showed that they had noticeably different load profiles. Therefore, absolute energy savings between the two units could not be calculated. If the absolute savings measurement were desirable, then the existing RTU will have to be monitored for 1 year, followed by a year of monitoring of the Rebel unit after it replaces the existing RTU.

Other issues related to the installation of the Rebel unit included:

- The Rebel unit came with a different base footprint from the existing Lennox unit. Although a curb adapter was provided, it left the unit suspended over the front side of the base, and was ultimately supported by blocks.

- Although the new Rebel unit was considerably heavier than the unit it replaced, no roof reinforcement was needed.

The store that had the Rebel unit reported no comfort issues either positive or negative. The Rebel unit had a Micro Tech III controller, which was not compatible with the existing Emerson E2 BX controller, or the Emerson building automation system (BAS). Emerson had an application for the Micro Tech II controller but not for Micro Tech III. Therefore, the store had to install an output board with a set of dry contacts to control the RTU indoor fan. They also had to add an interface to monitor the indoor fan "On/Off" status and the supply/return temperatures, but they could not control any cooling/heating/speed control functions. All operations were controlled directly by the Micro Tech III controller in the unit with input from the zone temperature sensor.

The start-up and commissioning of the Rebel was challenging because the local Daikin distributor who installed the unit had very little experience in installing these new units. In addition, the controller had many features with a large instruction/operation manual, which made it difficult to properly configure. It took the distributor a couple of trips to configure the unit correctly, but after it was configured, the unit, as well as its metering and monitoring system worked as expected. Over the last 12-month period, maintenance requirements for this unit were similar to the other units. 


\section{Contents}

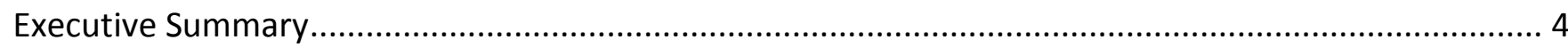

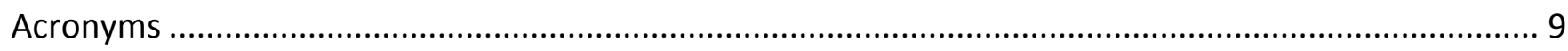

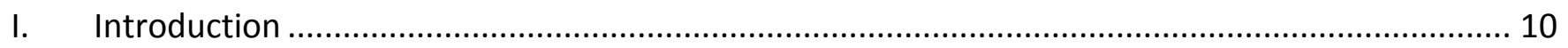

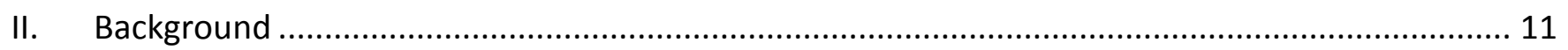

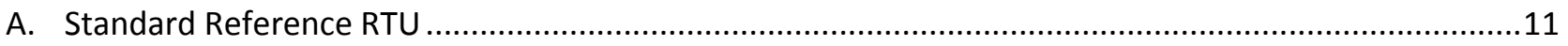

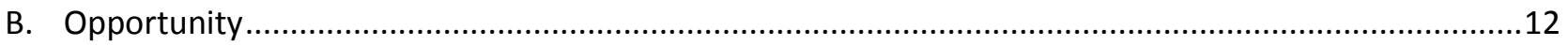

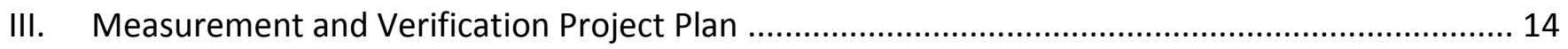

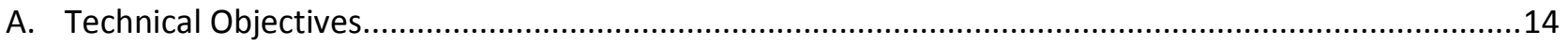

B. Demonstration Project Plan ..................................................................................................

C. Technology Description - RTU Challenge Unit - Rebel .....................................................................15

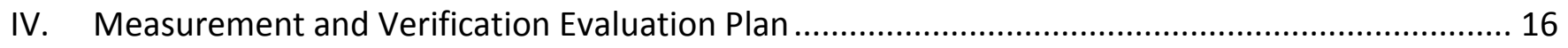

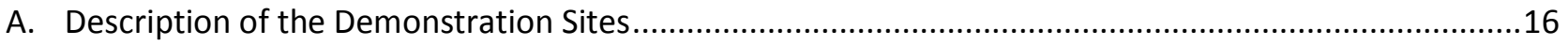

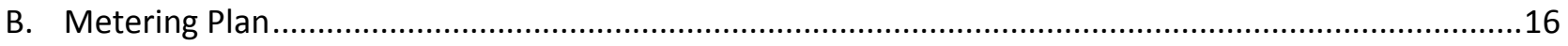

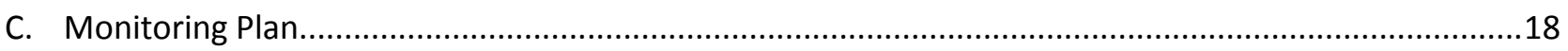

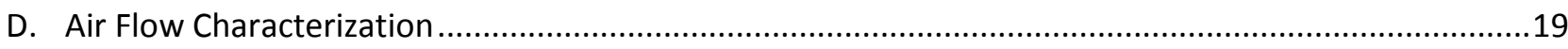

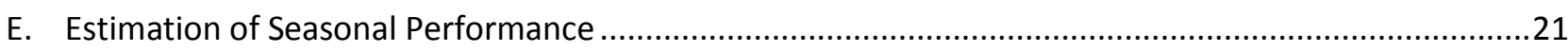

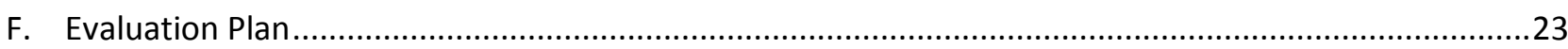

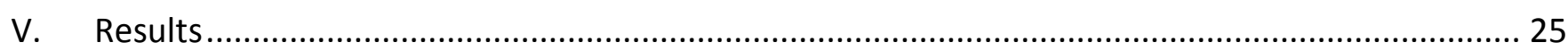

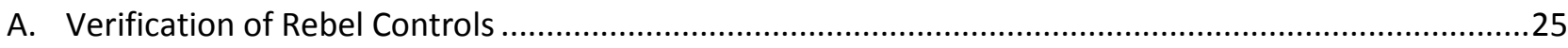

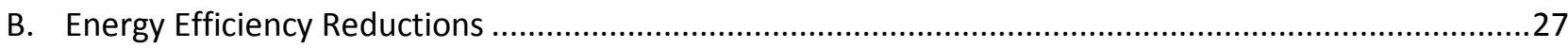

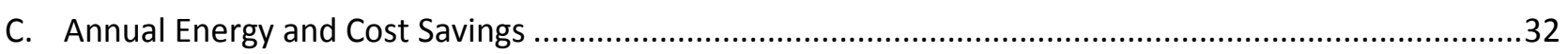

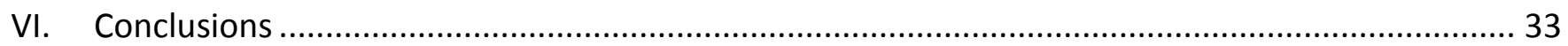

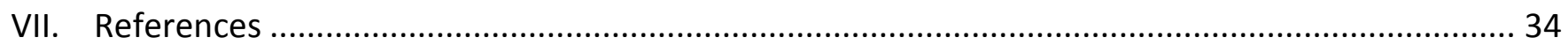




\section{Figures}

Figure 1: Daikin Rebel Unit (Source: Daikin). Reprinted with permission from Daikin ................................... 15

Figure 2: Schematic of tested RTU Configuration with Sensor Locations ..................................................... 17

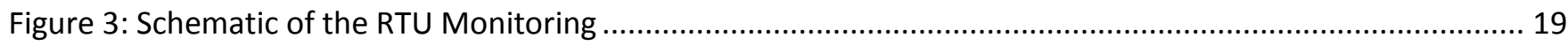

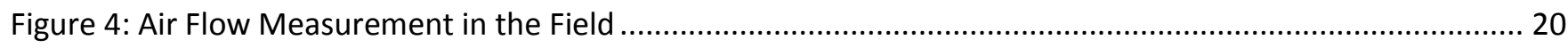

Figure 5: Correlation of Measured Air Flow as a Function of the Fan Speed for the Rebel Unit ........................ 21

Figure 6: Rebel Unit Profiles of Supply-fan Speed, Space Temperature and Operational Mode on a Typical Day

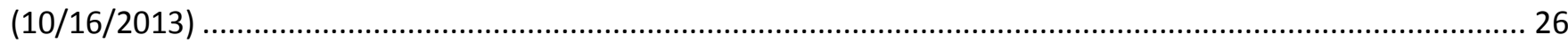

Figure 7: Rebel Unit Profiles of Supply-air Temperature, Percentage Cooling, and Operational Mode on a Typical

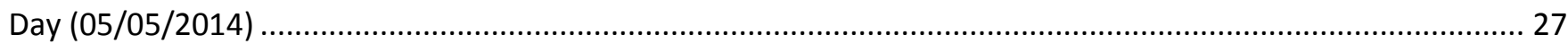

Figure 8: Compressor and Fan Run Time for the Reference unit when the Unit is either in Cooling or Ventilation

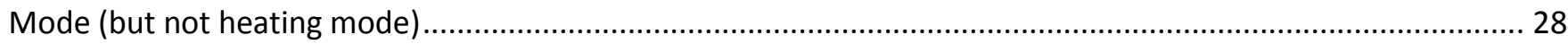

Figure 9: Compressor and Fan Run Time for the Rebel Unit when the Unit is in either Cooling or Ventilation

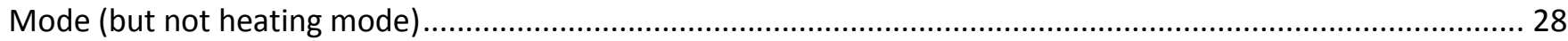

Figure 10: Comparison of Energy Efficiency Ratio of the Reference Unit and the Rebel Unit............................ 29

Figure 11: Comparison of Daily Energy Efficiency Ratio of the Reference Unit and the Rebel Unit as a Function of

Daily Average Outdoor-air Temperature for the Monitoring Period ................................................................ 30

Figure 12: Ratio of Rebel EER and the Reference Unit as a Function of Daily Average Outdoor-air Temperature 31 


\section{Tables}

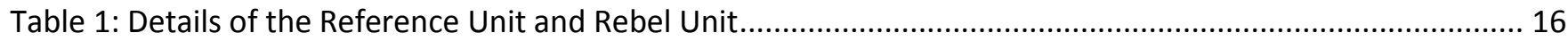

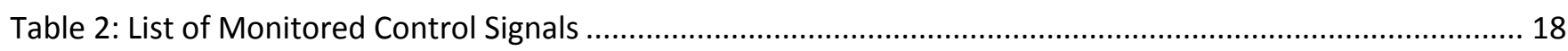

Table 3: Comparison of Seasonal EER between Rebel and the Reference Unit................................................. 32 


\section{Acronyms}

$\begin{array}{ll}\text { AHRI } & \text { Air-Conditioning, Heating and Refrigeration Institute } \\ \text { ARC } & \text { advanced rooftop control } \\ \text { ASHRAE } & \text { American Society of Heating, Refrigeration and Air-Conditioning Engineers } \\ \text { BAS } & \text { building automation system } \\ \text { BBA } & \text { Better Building Alliance } \\ \text { BTO } & \text { Buildings Technologies Office } \\ \text { CFM } & \text { cubic feet per minute } \\ \text { DOE } & \text { U.S. Department of Energy } \\ \text { ECM } & \text { electronic commuted motor } \\ \text { EER } & \text { energy efficiency ratio } \\ \text { EIA } & \text { Energy Information Administration } \\ \text { ERV } & \text { energy recovery ventilator } \\ \text { GPG } & \text { Green Proving Ground } \\ \text { GSA } & \text { General Services Administration } \\ \text { HVAC } & \text { heating, ventilation and air conditioning } \\ \text { IEER } & \text { integrated energy efficiency ratio } \\ \text { M\&V } & \text { measurement and verification } \\ \text { RTU } & \text { rooftop air-conditioning unit }\end{array}$




\section{Introduction}

Packaged rooftop air-conditioning units (RTUs) are used in 46\% (2.1 million) of all commercial buildings, serving over $60 \%$ (39 billion square feet) of the commercial building floor space in the U.S. (EIA 2003). The primary energy consumption associated with RTUs is over 2.6 quads annually. Therefore, even a small improvement in efficiency or part-load operation of these units can lead to significant reductions of energy use and carbon emissions.

Starting in 2011, the U.S. Department of Energy's Building Technology Office (DOE's BTO) funded a series of projects related to RTUs. Some projects were to improve the operating efficiency of the existing RTUs while others were focused on improving the operating efficiency of new units. This report documents the testing of a state-of-art RTU unit and a standard reference unit in the field and compares the seasonal efficiency of the two units. Section III provides the background for the work. Section IV describes the measurement and verification plan for the field tests. Section $V$ describes the measurement and verification evaluation plan. The results are described in Section VI. The lessons learned and recommendations for future work are described in Section VII. A list of references is provided in Section VIII. 


\section{Background}

In 2011, the U.S. Department of Energy's Building Technology Office (DOE's BTO), with help from the Better Buildings Alliance (BBA) members, developed a specification for high performance rooftop air-conditioning units (also known as the RTU Challenge) with capacity ranges between 10 and 20 tons (DOE 2013). The goal of the RTU Challenge was to spur the market introduction of cost-effective, high-performance commercial rooftop unit air conditioners. Two manufacturers produced rooftop air-conditioning units (RTUs) - Daikin Rebel and Carrier WeatherExpert - that met RTU Challenge specifications. These units were tested and rated at the standard conditions by manufacturers and both had integrated energy efficiency ratio (IEER) of over 18 . Because the performance ratings at standard conditions do not necessarily represent the "true" seasonal energy efficiency, field tests were needed to provide more realistic performance comparisons in "real" conditions. This report provides results from comparing the seasonal field performance of a Rebel unit and a standard reference RTU.

\section{A. Standard Reference RTU}

The rated energy efficiency ratio (EER) of a reference unit in the field, depending on the vintage, can range from a low of 8 to a high of 12 . In addition to the EER, most reference RTUs in the field have the following characteristics:

- $\quad$ Standard RTU typically has a constant-speed supply fan. When the RTU operates, its supply fan always runs at full speed (100\%) regardless of the operational modes (e.g., heating, cooling and ventilation).

- Smaller RTUs that are less than 7.5 tons, usually have a single-stage cooling. A single-stage unit has one constant-speed compressor cycling on and off to meet the space cooling loads. Units 7.5 tons and larger usually have two or more stages of cooling. A multi-stage unit has two or more constantspeed compressors of equal size. The switch from first stage to second (or higher) stage can be based on either the space temperature deviation from the cooling set point or the time lag for not reaching the cooling set point.

- $\quad$ Most RTUs in the field use a gas furnace for heating; some use electric resistance heat. The gas furnace cycles on and off to meet the space heating loads.

- Most RTUs 7.5 tons or larger are required to have air-side economizers in most regions of the country. The only exceptions are smaller units ( $<7.5$ tons) and the units located in hot/humid climates (e.g. Florida, Texas, etc.). 


\section{B. Opportunity}

Most reference RTUs in the field have constant-speed supply fans designed to provide ventilation at the design rate at all times when the fan is operating. Although there are a number of hours during the day when a building may not be fully occupied or the need for ventilation is lower than the maximum design rate, the ventilation rate cannot be adjusted easily with a constant-speed fan. Supply fan energy savings can be achieved by modulating the supply fan speed during the ventilation mode and potentially during mechanical heating/cooling, if the unit has multiple stages of heating/cooling. When the building is occupied and the unit is in ventilation mode, the role of the supply fan is to provide fresh air to maintain proper indoor air quality in the spaces that it is serving.

Similarly, most RTUs in the field have constant-speed compressors that cannot modulate to provide the required capacity; therefore, they are cycled on and off. Cycling creates inefficiencies. Significant savings are possible with a unit that has a variable- or multi-speed fan and variable-speed compressors.

Wang and Katipamula (2013) conducted a detailed simulation of one RTU Challenge unit (Rebel) and compared its performance to a number of reference units for a prototypical big-box retail store. The model used the new performance curves along with detailed energy management control code to estimate the energy consumption of the prototypical big-box retail store in three locations (Houston, Log Angeles and Chicago). The energy consumption of the big-box store using the Rebel unit was then compared to a big-box store that used three different reference units. The first reference unit (Reference 1) represented existing rooftop units (RTUs) in the field, so it was considered as the baseline to estimate potential energy savings from other RTU replacement options. The second reference unit (Reference 2) represented RTUs in the market that just meet the current (2013) Federal regulations for commercial equipment standards. It was used as the baseline to estimate the potential for energy savings from Rebel units in comparison with new RTUs that meet the minimum efficiency requirements. The third reference unit (Reference 3) represented the latest ASHRAE 90.1-2010 requirements. For RTUs with cooling capacity greater than 11,000 Btu/h, ASHRAE 90.1-2010 (ASHRAE 2010) requires two-speed fan control or variable-speed fan control.

The following conclusions were drawn from the comparison of annual energy cost for RTU Challenge unit with the three reference units:

- Using Reference 1 as the baseline, Rebel units led to about 45\% lower heating, ventilation and air conditioning (HVAC) energy costs (electricity and gas combined) in Houston and Los Angeles, and $33 \%$ lower cost in Chicago. The HVAC electricity cost savings was around $50 \%$ for all three locations.

- Using Reference 2 as the baseline, Rebel units led to about 37\% lower HVAC energy costs in Houston, $40 \%$ lower cost in Los Angeles, and $29 \%$ lower cost in Chicago. The HVAC electricity cost savings was $40 \%, 42 \%$, and $50 \%$, respectively in those three locations.

- Using Reference 3 as the baseline, Rebel units led to about 27\% lower HVAC energy costs in Houston, 18\% lower cost in Los Angeles, and 15\% lower cost in Chicago. The HVAC electricity cost savings was $30 \%, 19 \%$, and $28 \%$, respectively in those three locations. 
Based on the simulation results, the Rebel RTU Challenge unit, if widely adopted, could lead to significant energy, cost and emission reductions. Because the cost of these units was not available and because the costs would be specific to a given installation, no attempt was made to estimate the potential payback periods associated with any of the three reference scenarios. However, if the incremental cost for any of the three reference cases is known, one can easily estimate a simple payback period. 


\section{Measurement and Verification Project Plan}

This section describes the measurement and verification project plan that addressed the technical objectives of the field demonstration. This section describes the technical objectives, the plan to execute the technical objectives and a description of the RTU Challenge unit.

\section{A. Technical Objectives}

The objective of this field demonstration was to quantify the seasonal energy efficiency of the RTU Challenge unit and also to compare its seasonal performance with a standard reference unit in the field.

\section{B. Demonstration Project Plan}

The rated efficiency of the RTU Challenge unit was 50\% above the current ASHRAE 90.1-2013 Standard. Because the standard rated test and the IEER (integrated energy efficiency ratio) tests did not represent the "true" seasonal energy efficiency, field tests and demonstrations were needed to show the potential savings of these high performance units. The planned field demonstrations provided more realistic performance comparisons in "real" conditions. The field demonstrations allowed for: 1) comparison of the annual performance of the RTU Challenge unit to a standard unit it was replacing; 2 ) verification of the proper operation of RTU Challenge unit controls, such as economizer controls and variable-speed fan controls; 3 ) identification of non-performance related issues, such as maintenance requirements; and 4) capturing lessons learned.

Because only a limited number of field demonstrations could be done, the demonstrations needed to be representative of the potential applications of RTU Challenge units. Packaged RTUs were more widely used in retail and office type buildings. Considering that the Better Building Alliance (BBA) members were the driving force of adopting RTU Challenge units, retail buildings were expected to be the predominant building type in field demonstrations. Therefore, this demonstration focused on a retail building.

The goal of the RTU Challenge demonstration was to estimate the seasonal performance of the RTU Challenge unit and the annual savings that could be achieved by installing the challenge unit instead of an alternate standard unit. The standard unit (the unit that would have been installed if not for the RTU Challenge unit) was metered and monitored over 9 months before the RTU Challenge unit was installed to establish both the seasonal efficiency and annual energy consumption. However, this approach could have taken over 24 months

to complete the collection and the analysis of data. To reduce the field evaluation period to between 12 and 18 months, an alternate approach was devised.

The alternate approach relied on monitoring two units simultaneously: 1) standard unit and 2) RTU Challenge unit. Because monitoring of the RTU Challenge unit and the standard unit was done simultaneously, the field measurement and verification was completed within 12 months. This alternate approach worked because the two monitored RTUs were the same size, had the same external pressure drop and served spaces with similar load profiles. For this alternate approach, two identical retail facilities were selected in the same location with RTUs that served identical spaces, with one facility having the standard unit and the other the RTU Challenge unit. If this alternate approach was not feasible, then two similar spaces in the same building could also have been used, with one space having a standard unit and other space having the RTU Challenge unit. 
If the two spaces had similar loads, operating hours and space temperature set points, the alternate approach provided reasonable results. However, if the space loads were different, the annual energy consumption (required to estimate the annual savings) could have higher uncertainty. Irrespective of space load, the comparison of seasonal efficiency between the two units was still valid.

\section{Technology Description - RTU Challenge Unit - Rebel}

The Daikin Rebel packaged rooftop system was the first unit to meet DOE's RTU Challenge specification. The 10ton air-conditioner has two compressors with one variable-speed inverter-driven compressor, composite condenser fan(s) with variable-speed ECM (electronic commuted motor) motors, MicroTech ${ }^{\circledR}$ III controls that can be integrated with optional BACnet or LonMark building automation systems, and electronic expansion valves (Figure 1). Unlike the conventional units, Rebel modulates the supply fan in response to the zone conditions and modulates the compressor speed to maintain supply-air temperature set points.

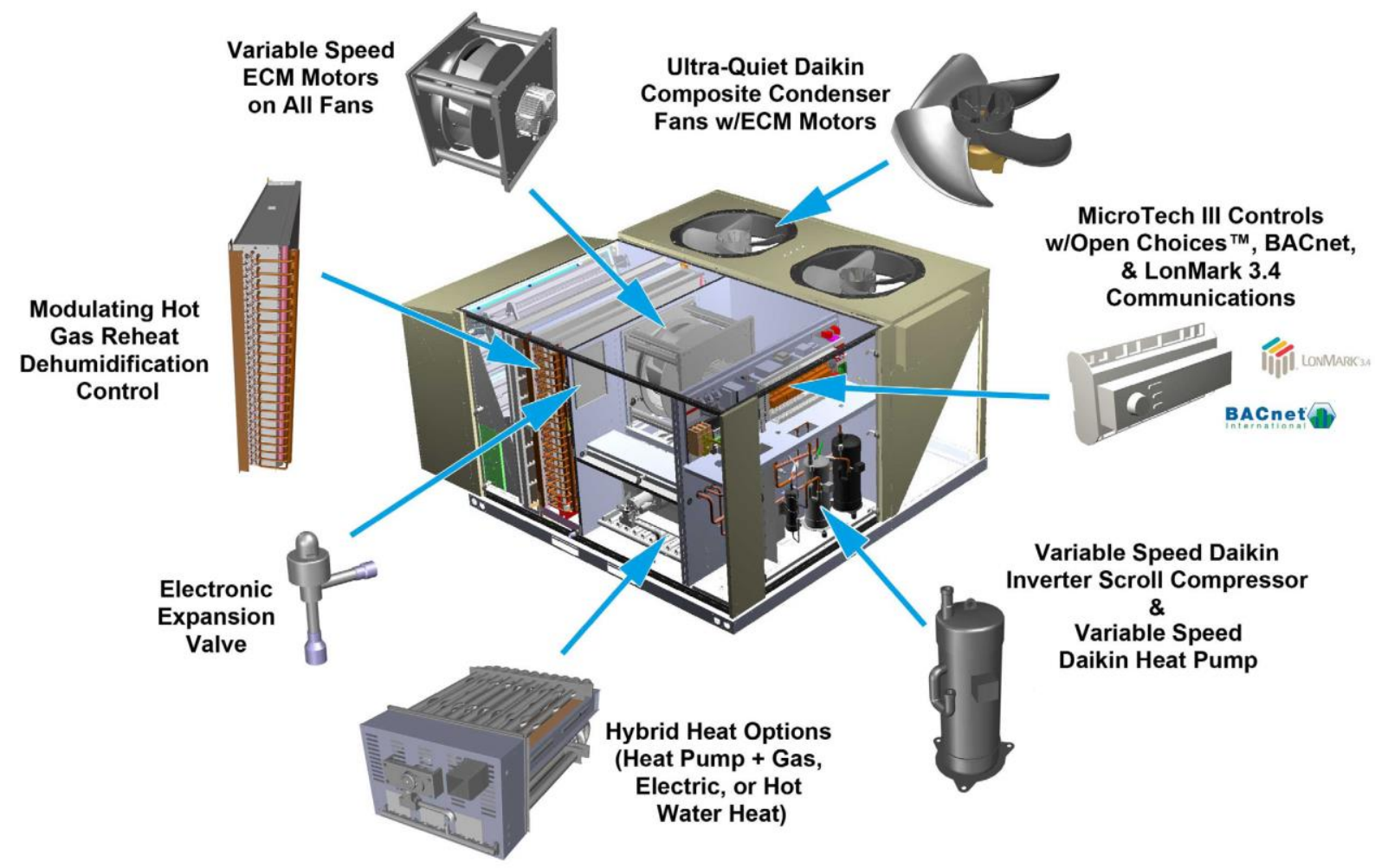

Figure 1: Daikin Rebel Unit (Source: Daikin). Reprinted with permission from Daikin 


\section{Measurement and Verification Evaluation Plan}

The measurement and verification (M\&V) evaluation plan used to quantify the seasonal performance of the RTU Challenge and the standard reference unit is described in this section.

\section{A. Description of the Demonstration Sites}

The demonstration took place at two grocery stores located in New Smyrna Beach and Port Orange, Florida. Table 1 provides the details of the two units. The Rebel unit (Model\# DPS007A) was installed as a replacement of an existing unit in July 2013 at the New Smyrna Beach store. The reference unit (Lennox Model \# LCA-090H4) was an existing rooftop unit in the Port Orange store that had been in the field for about 6 years. The reference unit had two compressors for staged cooling and a constant-speed supply fan. The two units had a rated cooling capacity of 7.5 tons. The reference unit had electric resistance heating coils with a capacity of $22.5 \mathrm{~kW}$ while the Rebel had 18-kW heating capacity. The two units served the store's office spaces with similar footprints. These two stores were 12 miles apart so the climate conditions were similar. They also had very similar operating schedules: the New Smyrna Beach store operated from 7:00 a.m. to 10:00 p.m., Monday to Sunday; the Port Orange store operated from 7:00 a.m. to 10:00 p.m., Monday to Saturday, and from 7:00 a.m. to 9:00 p.m. on Sunday.

\section{Table 1: Details of the Reference Unit and Rebel Unit}

\begin{tabular}{|l|l|r|r|r|r|l|}
\hline $\begin{array}{l}\text { RTU } \\
\text { Monitored }\end{array}$ & Model & Vintage & $\begin{array}{l}\text { Rated Cooling } \\
\text { Capacity (ton) }\end{array}$ & Rated EER & $\begin{array}{l}\text { Rated Heating } \\
\text { Capacity (kW) }\end{array}$ & $\begin{array}{l}\text { Design Air } \\
\text { Flow Rate } \\
\text { (CFM) }\end{array}$ \\
\hline Reference & $\begin{array}{l}\text { Lennox Model \# } \\
\text { LCA-090H4 }\end{array}$ & 2008 & 7.5 & 11.1 & 22.5 & 2860 \\
\hline Rebel & $\begin{array}{l}\text { Daikin Model\# } \\
\text { DPSO07A }\end{array}$ & 2013 & 7.5 & 12.5 & 18 & 3530 \\
\hline
\end{tabular}

\section{B. Metering Plan}

Both Rebel and the reference units in the field were similarly configured, as shown in Figure 2. The schematic (Figure 2) also shows the locations of the sensors for the two units. Outdoor-air came from the energy recovery ventilator (ERV) through the return-air ductwork. The ERV operation was interlocked with the RTU operations. The ERV reduced the sensible cooling loads on the unit while meeting ventilation requirements (outdoor air). 


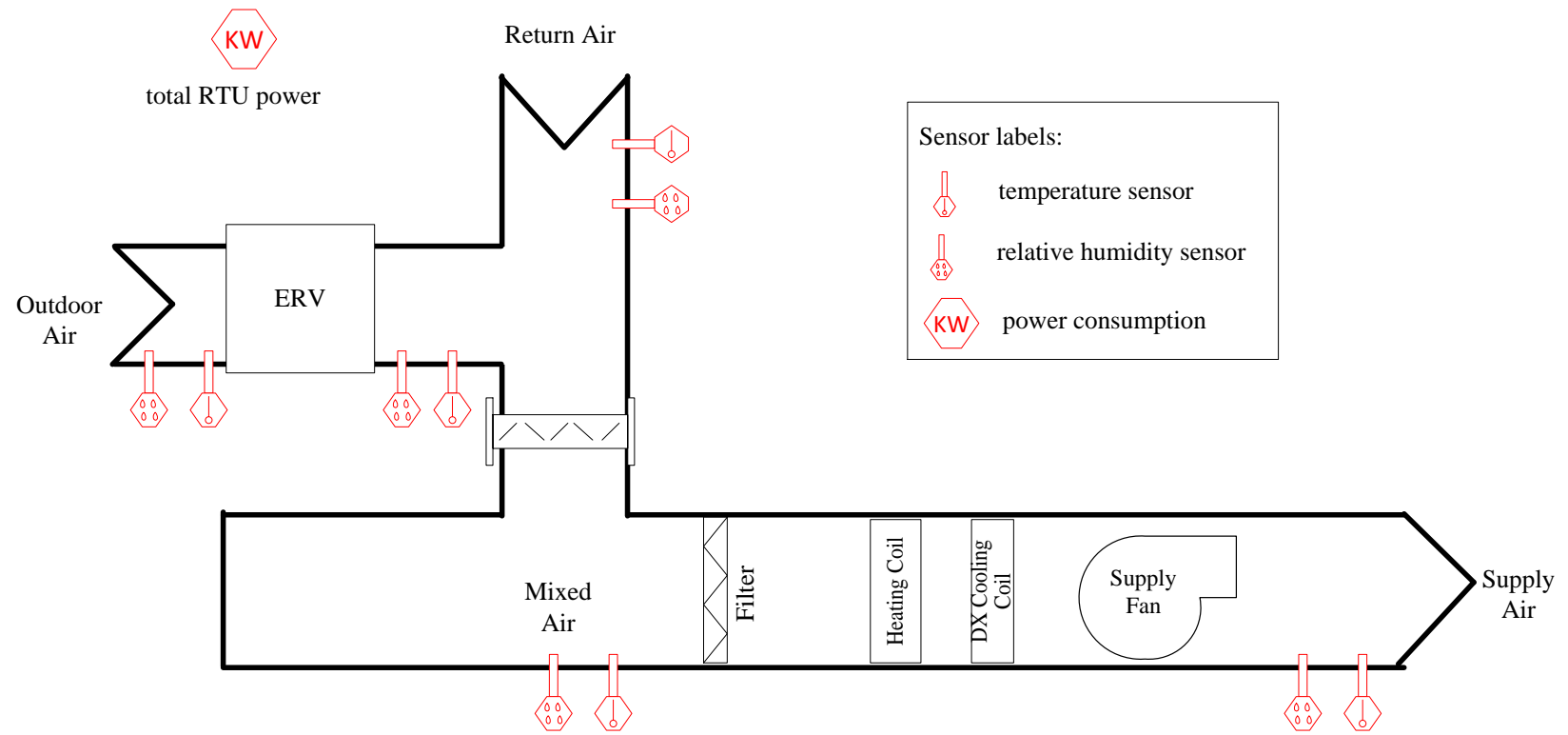

Figure 2: Schematic of tested RTU Configuration with Sensor Locations

The following sensors were used in the field test:

- For both units, a set of sensors were used to measure the dry-bulb temperature and the relative humidity for the outdoor-air, the return-air, the air discharged from ERV, the mixed-air, and the supplyair. The accuracy of the temperature sensor was $\pm 0.36^{\circ} \mathrm{F}$ in the operating temperature range $\left(40^{\circ} \mathrm{F}\right.$ to $\left.120^{\circ} \mathrm{F}\right)$. The accuracy of the relative humidity sensor was $\pm 5 \%$ in the operating relative humidity range (0\% to $100 \%)$.

- RTU total power consumption was measured using a power transducer with an accuracy of $\pm 0.5 \%$ of reading.

In addition to temperature, relative humidity and power measurements, a number of control signals were either directly monitored from the RTU controller (for the reference unit) or through a BACnet protocol translator device that is connected to the RTU controller (for the Rebel unit). Table 1 lists all control signals that were monitored. Although Figure 2 does not show a supply-fan power measurement sensor, supply-fan power was indirectly measured. It was computed using the total unit power measurement when the compressor was not running for the standard unit with a constant-speed supply fan. For the variable-speed supply fan, the supply fan power consumption was estimated based on the fan speed and fan affinity laws. Note that supply fan power was not required for performance characterization or energy savings estimate. 
Table 2: List of Monitored Control Signals

\begin{tabular}{|c|c|c|}
\hline Control Signal & Description & Applicable RTUs \\
\hline FanCall & Fan signal from thermostat & Reference \\
\hline CoolCall1 & $1^{\text {st }}$ stage cooling signal from thermostat & Reference \\
\hline CoolCall2 & $2^{\text {nd }}$ stage cooling signal from thermostat & Reference \\
\hline HeatCall1 & $1^{\text {st }}$ stage heating signal from thermostat & Reference \\
\hline HeatCall2 & $2^{\text {nd }}$ stage heating signal from thermostat & Reference \\
\hline UnitState & $\begin{array}{l}\text { One of eight unit operating stages (1-8): } 1 \text { (off), } 2 \\
\text { (startup), } 3 \text { (recirculation), } 4 \text { (fan only), } 5 \text { (minimum } \\
\text { supply-air temperature set point) , } 6 \text { (heating), } 7 \\
\text { (economizer), and } 8 \text { (mechanical cooling) }\end{array}$ & Rebel \\
\hline FanSpeed & Speed of the variable-speed drive for the supply fan & Rebel \\
\hline ClgStatus & $\begin{array}{l}\text { Indication of whether or not mechanical cooling is } \\
\text { currently allowed. If cooling is disabled, the reason is } \\
\text { indicated ( } 1 \text { = enabled) }\end{array}$ & Rebel \\
\hline ClgCapacity & $\begin{array}{l}\text { The percentage of the unit maximum cooling } \\
\text { capacity currently operating }\end{array}$ & Rebel \\
\hline ControllerDown & Indication of loss of communications for monitoring & Rebel, Reference \\
\hline
\end{tabular}

\section{Monitoring Plan}

The monitoring plan consisted of collection of data at each RTU at 1-minute intervals, storing it locally on the roof, and streaming the data in real time to the Cloud for analysis. The cellular network was used to upload data from each site to the Cloud. In case of loss of communication between the site and Cloud, the logged data was stored locally at each site with a maximum storage capacity of a few days. Figure 3 schematically shows the entire monitoring process. Each of the two sites was configured with a Jace-202-XPR-24 (Java Application Control Engine) device that was connected to the cellular network (via the wireless modem). The Jace provided the interface to the Catalyst-371 controller and input/output device that was installed on each RTU and also served as a data logger. 


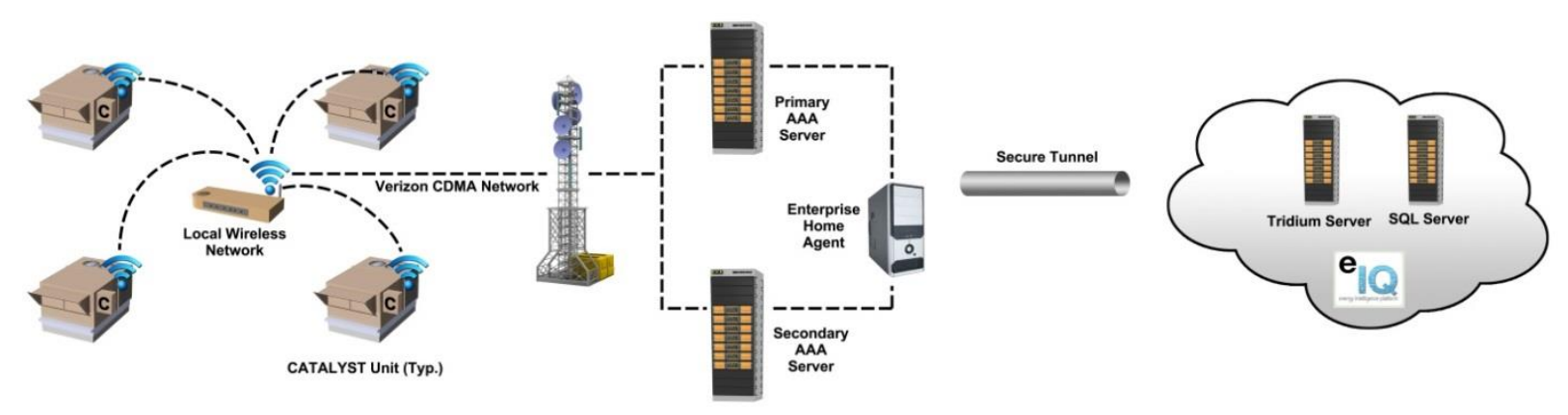

Figure 3: Schematic of the RTU Monitoring

\section{Air Flow Characterization}

Building owners and facility managers understand the concept of seasonal efficiency, but to calculate this performance metric, supply-air flow measurements are required. Measurement of air flow on a continuous basis is difficult in a RTU because of the physical constraints imposed by the shape and size of the RTU. However, one-time air flow characterization is possible in the field using flow plates that can be inserted by temporarily replacing the air filters. For the standard unit, the air flow was constant, so there was just one measurement to make. For the RTU Challenge unit, the supply air flow varied with fan speed. Therefore, air flow was measured at various fan speeds to create an air flow model as a function of fan speed.

To characterize the air flow rate, the correlation between the supply-fan speed and the air flow rate was derived from a series of one-time field measurements of air flow rates at various fan speeds. Based on the correlation and the monitored fan speed, the air flow rate was estimated as a function of fan speed.

Using calibrated circular flow plates in a rectangular housing that were inserted in the air filter rack, the air flow was estimated. This device is designed to measure the velocity pressure (total pressure - static pressure) reading, which is then converted to actual air flow. The air flow measuring device was placed in the air filter rack after the removal of the air filters. Once the air flow measuring device was installed, any gaps were sealed with cardboard and cellophane to ensure all air flow was routed through the measuring devices (see Figure 4 below). The RTU access door was closed (but not shut tight) to ensure the pressure tubes were not pinched. A vendor device with gages was connected to the air flow measuring device and readings were converted to CFM values. Clear cellophane (seen in Figure 4) was used to cover all access door openings (top, bottom and sides) as well as the door handles, to ensure a tight seal and minimize all air flow leakage around the pressure tubes. The flow plates are designed so that the typical pressure drop across the measuring devices is less than or approximately equal to that of a typical filtration device that would normally be installed at the same location.

The air flow measuring device was used to 1) measure the maximum air flow rate for the reference unit; and 2) measure the air flow rates at different fan speeds for the Rebel unit. Because the standard reference unit had a constant speed supply fan, only one reading was necessary. For the reference unit, after the flow plates were installed and the access door's gaps were sealed, a number of air flow readings were taken over a period of 30 minutes and averaged. The reference unit had a supply flow rate of 2,860 CFM. 
For the Rebel unit, a number of air flow readings between $40 \%$ and $100 \%$ supply fan speed were recorded after the air flow plates were installed and the access door gaps sealed. The readings were taken once every 5 to 10 minutes over a 2-hour period at different fan speeds. Multiple readings were taken at each fan speed and the readings were averaged to characterize the air flow as a function of fan speed. As shown in Figure 5, there is a linear relationship between air flow rate and fan speed for the Rebel Unit as expected.

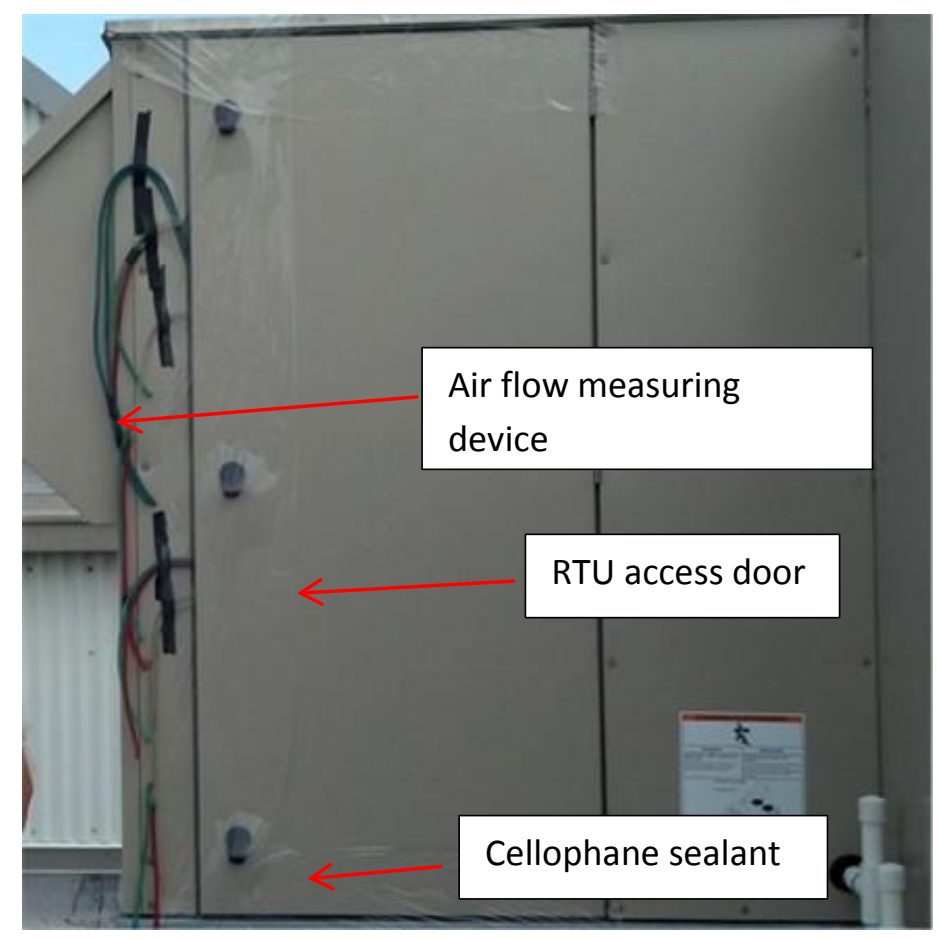

Figure 4: Air Flow Measurement in the Field 


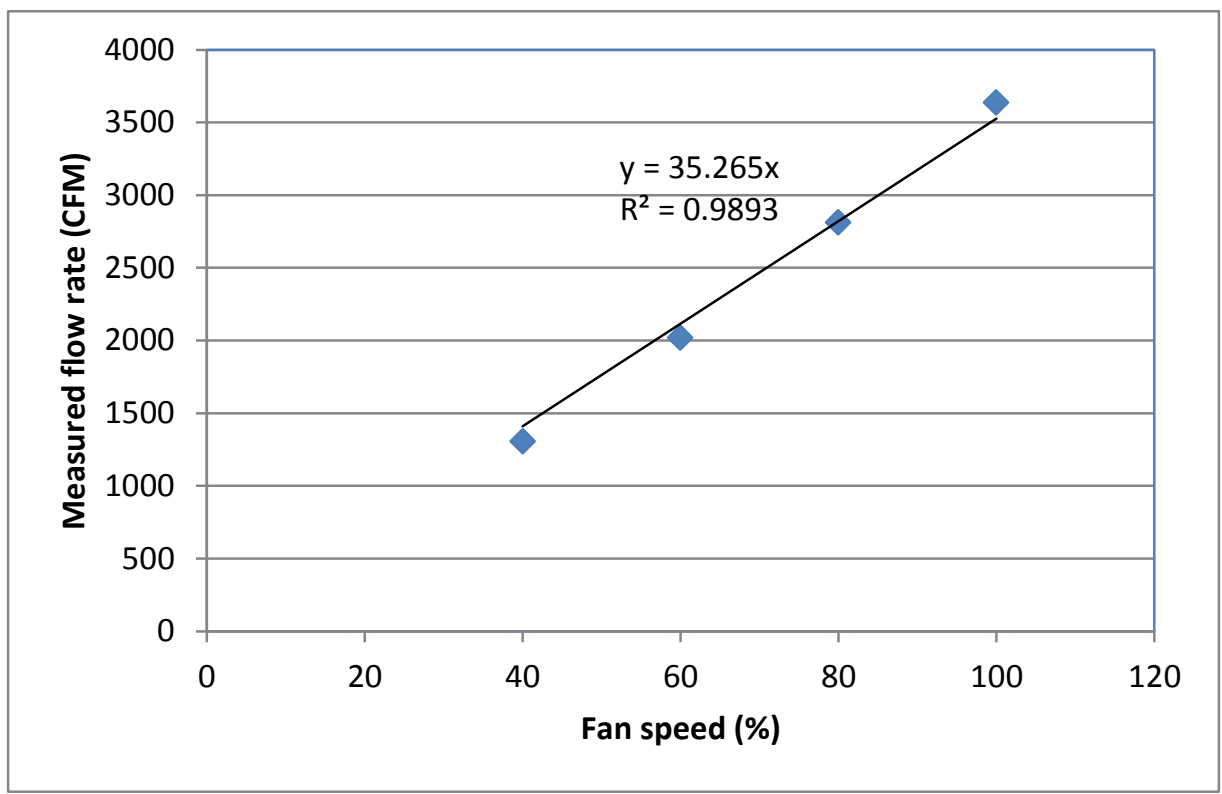

Figure 5: Correlation of Measured Air Flow as a Function of the Fan Speed for the Rebel Unit

\section{E. Estimation of Seasonal Performance}

The cooling efficiency of both units was computed and compared over the monitoring period. The seasonal efficiency was characterized as variation of the efficiency as a function of outdoor/indoor conditions and also a single annual index. The estimated air flow rate was used together with the measured temperature and relative humidity of mixed-air and supply-air streams to calculate the total delivered cooling capacity. The ratio of total daily delivered cooling and total daily unit power provided a daily efficiency of the RTUs. The seasonal efficiency of RTUs was similarly computed as a ratio of total cooling capacity over the season and total unit power consumption over the season.

The following steps were needed to process the measured data for both the RTU Challenge unit and the reference unit:

Step 1. Identified and removed data records that show evidence of incorrect measurement (outliers).

Outliers of measured data resulted from communication issues and data logging problems. These problems occurred randomly and constituted a very small fraction of the total data over the monitoring period.

Step 2. Calculated the specific enthalpy (Btu/lb) of mixed-air and supply-air streams based on the measured dry-bulb temperature $\left({ }^{\circ} \mathrm{F}\right)$ and relative humidity.

Step 3. Calculated the mass flow rate, $\dot{\mathrm{m}}(\mathrm{lb} / \mathrm{h})$ of the supply air at each minute using the supply fan speed.

Because the reference unit had a constant speed fan, its air flow rate was fixed at 2,860 CFM. Thus, the mass flow rate $\dot{\mathrm{m}}$ was calculated as: 


$$
m_{\text {ref }}= \begin{cases}4.5 \frac{l b}{f t 3} \frac{\mathrm{min}}{h} * 2,860 \frac{f t 3}{\min }=12,870 \frac{l b}{h} & \text { (if FanCall }=1) \\ 0 & \text { (if FanCall }=0)\end{cases}
$$

where, FanCall was a monitored control signal indicating whether the supply fan was running (see Table 1).

Because the Rebel unit had a variable-speed supply fan, the air flow rate changed as a function of fan speed. As discussed previously, the correlation between fan speed and air flow rate was obtained using the one-time field measurements of fan speed and the corresponding air flow rate (Figure 5):

$\dot{V}=35.265 \frac{f t 3}{\min \%} *$ FanSpeed $\%$

where, $\dot{V}$ was the volume air flow rate in CFM, and FanSpeed was the speed of the variable-speed drive for the supply fan. The above linear regression was developed for fan speeds greater than $40 \%$, which was the minimum setting for the Rebel unit.

The mass flow rate $\dot{\mathrm{m}}(\mathrm{lb} / \mathrm{h})$ for Rebel was calculated as:

$\dot{m}_{\text {Rebel }}=4.5 \frac{l b}{f t 3} \frac{\min }{h} * \dot{V} \frac{f t 3}{\min }$

Step 4. Calculated the cooling rate delivered at each minute:

$\dot{Q}=\operatorname{MAX}\left\{0, \dot{m} \frac{l b}{h} *\left(h_{M A}-h_{S A}\right) \frac{B t u}{l b}\right\}$

where $\dot{Q}$ was the cooling rate in Btu/h, $h_{M A}$ and $h_{D A}$ were the specific enthalpy (Btu/lb) for the mixed air and the supply air, respectively (from Step 2 ).

Because the supply air could be cooled for several minutes after the compressor was off, compressor status was not used in Equation 4 to calculate the cooling rate. In addition, because the supply-air temperature sensor was located downstream of the supply fan (see Figure 2), the cooling calculated from Equation 4 was the air conditioner's net cooling, including heat gain from the supply fan motor.

Step 5. Calculated the daily cooling energy.

Equation 5 below was used to calculate the daily cooling energy (DailyCooling, in kBtu) provided by the reference unit and the Rebel unit.

DailyCooling $=\frac{\sum_{i} \dot{Q}_{l} \frac{B t u}{h}}{\left(60 \frac{1}{h} * 1000 \frac{B t u}{k B t u}\right)}$

where, the subscript $\mathrm{i}$ indicated the monitored 1-minute record.

Step 6. Calculated the daily electricity consumption in the cooling mode. 
For the reference unit, the compressor status could be determined by CoolCall1 and CoolCall2, which were the two control signals indicating the $1^{\text {st }}$ stage and $2^{\text {nd }}$ stage DX (direct expansion) cooling request from the thermostat. Equation 6 below was used to calculate the daily electricity consumption (DailyRTUElec, in kWh) when the compressor was ON for cooling.

DailyRTUElec $_{\text {Ref }}=\sum_{i}$ UnitPwr $_{i} \quad\left(\right.$ if CoolCall $1_{i}=1$ OR CoolCall $\left.2_{i}=1\right)$

where, UnitPwr was the measured total RTU power in kW.

For the Rebel unit, the compressor status could be determined by UnitState and ClgStatus. As described in Table 1, the compressor was ON for cooling when UnitState $=8$ and ClgStatus $=1$. Thus, the following equation was used to calculate DailyRTUElec:

DailyRTUElec $_{\text {Rebel }}=\sum_{i}$ UnitPwr $_{i} \quad\left(\right.$ if UnitState $_{i}=8$ AND ClgStatus $\left._{i}=1\right)$

Step 7. Calculated the daily cooling efficiency.

Energy Efficiency Ratio (EER) was used as the metric to measure cooling efficiency. Thus, daily cooling EER (kBtu/kWh) was calculated as:

DailyEER $=\frac{\text { DailyCooling }}{\text { DailyRTUElec }} \frac{k B t u}{k W h}$

Step 8. Calculated the seasonal cooling efficiency during the entire monitoring period.

Seasonal EER was used to measure the seasonal cooling efficiency. It was calculated as:

SEER $=\frac{\sum_{j} \text { DailyCooling }_{j}}{\sum_{j} \text { DailyRTUElec }_{j}} \frac{k B t u}{k W h}$

where the subscript $j$ indicated the number of calendar days over the entire monitoring period.

\section{F. Evaluation Plan}

The goal of RTU Challenge unit demonstration was to estimate the seasonal performance of the RTU Challenge unit and the annual savings that could be achieved from using the RTU Challenge unit compared to a unit that would have been used if not for the RTU Challenge unit. The reference unit (the unit that would have been used if not for the RTU Challenge unit) needed to be metered and monitored over 9 months before the installation of RTU Challenge unit to establish both the seasonal efficiency and annual energy consumption. However, this approach could have taken over 24 months to complete the collection and the analysis of data. Because of time constraints of completing the field evaluation within 12 to 18 months, an alternate approach was used.

The alternate approach relied on monitoring the reference unit and the RTU Challenge unit simultaneously at two different but similar sites. Because of the simultaneous monitoring, the field measurement and verification was completed within 12 months. This approach worked as long as the two monitored RTUs were of the same size, had same external pressure drop and served spaces with similar load profiles. For example, if two identical 
retail facilities in the same location were found, RTUs serving identical spaces could be monitored with one facility having the reference unit and the other having the RTU Challenge unit. If such an option was not feasible, two similar spaces in the same building could also be used, with one space served by the reference unit and other by the RTU Challenge unit.

If the two spaces had similar loads, operating hours and space temperature set points, the alternate approach could provide reasonable estimation of annual energy savings from RTU replacement. The methodology of energy savings estimation can be found in Wang et al. (2013). If the two spaces had different load characteristics, the regression model of RTU energy consumption developed for one space cannot be applied to the other space. As such, annual energy savings cannot be estimated in a reliable manner. However, irrespective of space load characteristics, the comparison of cooling efficiency between the two units is still valid for the alternate approach. For this demonstration, two similar sites close to each other were found, as described previously. 


\section{Results}

The results include two parts: 1) validation of the Rebel's controls and 2) comparison of performance of Rebel with standard reference unit.

\section{A. Verification of Rebel Controls}

In comparison with conventional packaged RTUs, the two major features of Rebel units included modulation of the supply fan speed in response to the zone conditions and the modulation of the compressor speed to maintain the supply-air temperature (Daikin 2013). These two features are verified in the following section using 1-minute interval monitored data.

Figure 6 shows the supply-fan speed, the space temperature, and the Rebel unit's operational mode (i.e., UnitState) for 10/16/2013 (an example day). As discussed in Section V (Table 1), the Rebel unit operated in the mechanical cooling mode when UnitState was equal to 8 and in the ventilation mode when UnitState was equal to 4 . This figure shows that:

- The supply fan ran at $40 \%$ of its full speed in the ventilation mode.

- The Rebel unit switched its operations modes between ventilation and mechanical cooling in the following manner: if the Rebel unit was in the ventilation mode, this mode continued until the space temperature rose above $72.9^{\circ} \mathrm{F}$; if the Rebel unit was in the mechanical cooling mode, this mode continued until the space temperature fell below $70.9^{\circ} \mathrm{F}$. When the Rebel unit switched from ventilation to mechanical cooling, the supply-fan speed gradually increased until the space temperature begain to decrease. The supply fan then maintained at that speed. Once the space temperature reached $70.9^{\circ} \mathrm{F}$, the supply fan gradually reduced its speed to $40 \%$ and the Rebel unit switched to the ventilation mode again. 


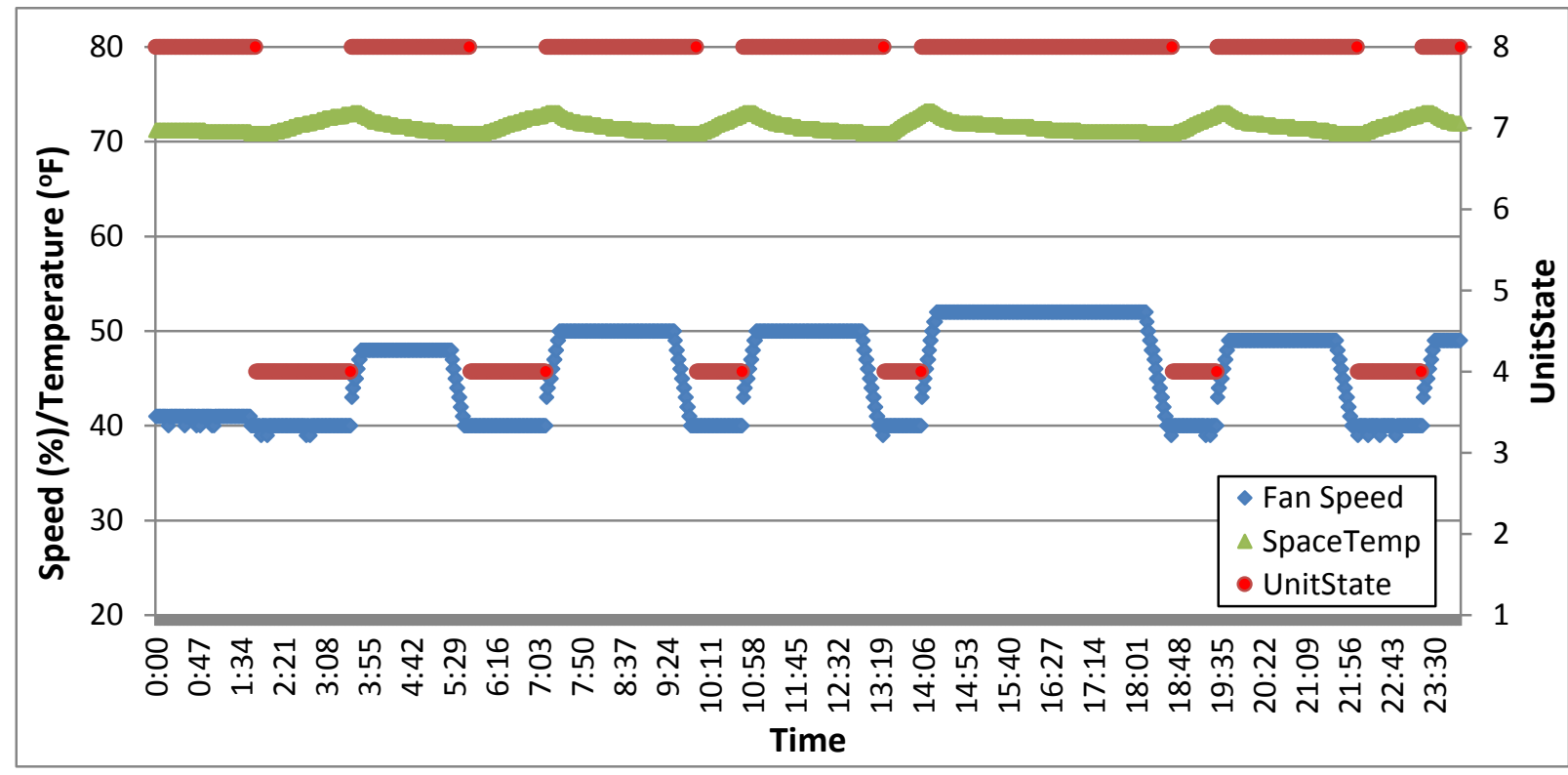

Figure 6: Rebel Unit Profiles of Supply-fan Speed, Space Temperature and Operational Mode on a Typical Day (10/16/2013)

Figure 7 shows the change of supply-air temperature (DATemp), the percentage of cooling capacity (ClgCapacity), and the operational mode (UnitState) on 05/05/2014. Because ClgCapacity represents the percentage of the maximum cooling capacity that the Rebel unit is running on, it can be reasonably used to indicate the compressor speed. This figure shows the following:

- The discharge-air temperature was maintained at $55^{\circ} \mathrm{F}$ during the mechanical cooling mode.

- During the mechanical cooling mode, the Rebel unit ran at different percentages of the maximum cooling capacity to maintain the constant supply-air temperature. This indicated that the compressor was modulating its speed to maintain supply-air temperature. 


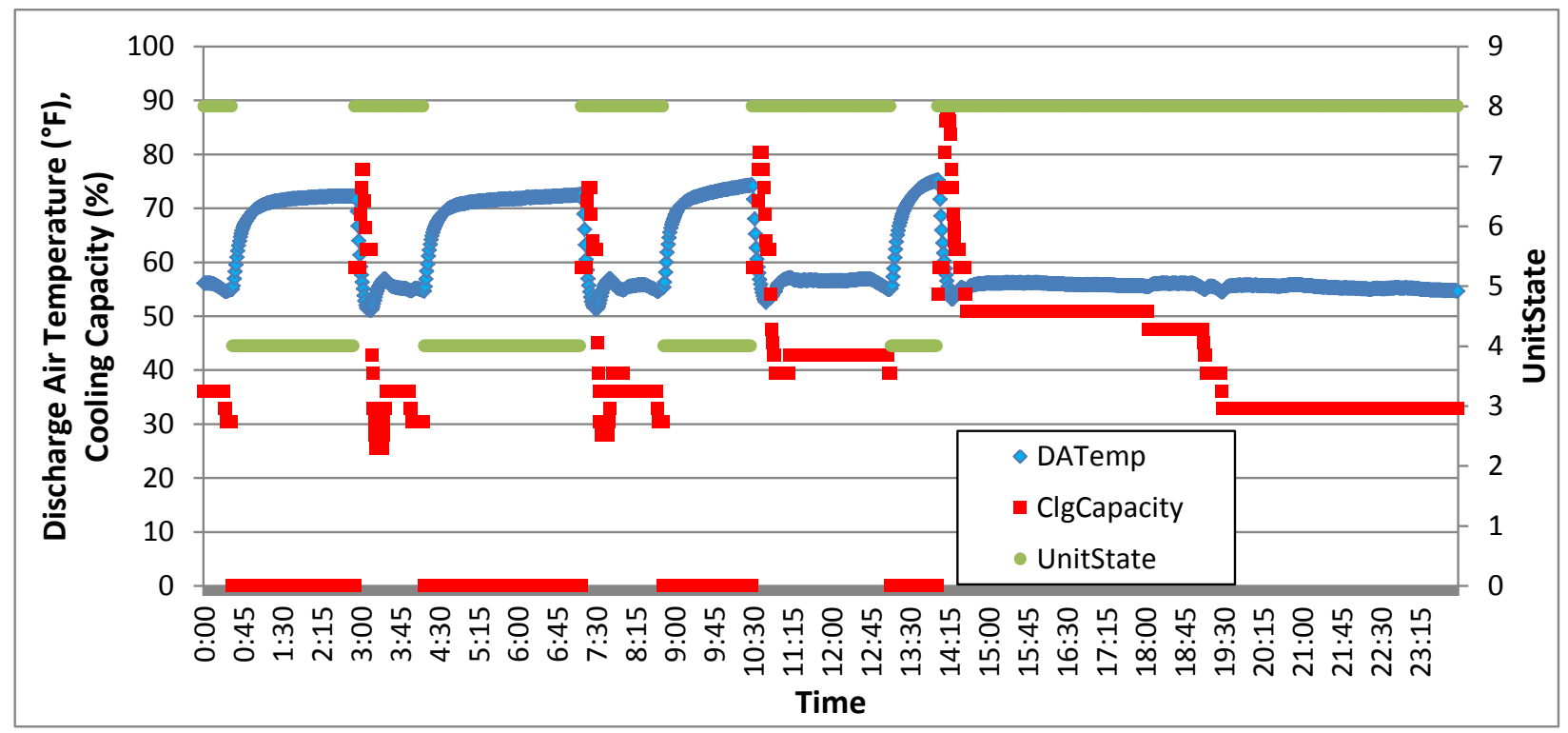

Figure 7: Rebel Unit Profiles of Supply-air Temperature, Percentage Cooling, and Operational Mode on a Typical Day (05/05/2014)

Based on the analysis of data (Figure 6 and Figure 7) the Rebel unit appeared to be operating as expected for the typical days chosen. Although data for only 2 days are presented, analysis of data from other days also confirmed this pattern.

\section{B. Energy Efficiency Reductions}

Using the procedure outlined in Section $\mathrm{V}$, the original 1-minute interval monitored data were processed to obtain daily cooling, daily electricity, and daily EER. The period of analysis for the standard reference unit included data from July 28, 2013 through September 6, 2014. For the Rebel unit, period of analysis included data from August 29, 2013 through September 6, 2014. As noted earlier, some data were filtered out because of problems with data logging and communication losses.

Although calculation of absolute energy savings was identified as one of the desired metrics, it was not possible because the units (standard and Rebel) were serving different loads (Figure 8 and Figure 9). The fan run time in these two figures included the times when the unit was in either cooling or ventilation modes, but excluded the times when the units ran in heating mode. Thus, for a given day, the difference between the fan and the compressor run times indicated the unit's operation time in ventilation mode. Figure 8 shows that the reference unit almost always operated in cooling mode except for some days in the heating season (from late November to March). In comparison, Figure 9 shows that the Rebel unit runs in cooling mode partially for most days. Because both units had the same rated cooling capacity, the difference in run time in cooling mode indicated that the spaces they served have different load characteristics. Therefore, the results presented in this section will focus on the comparison of cooling efficiency for these two units rather than the absolute energy savings. 


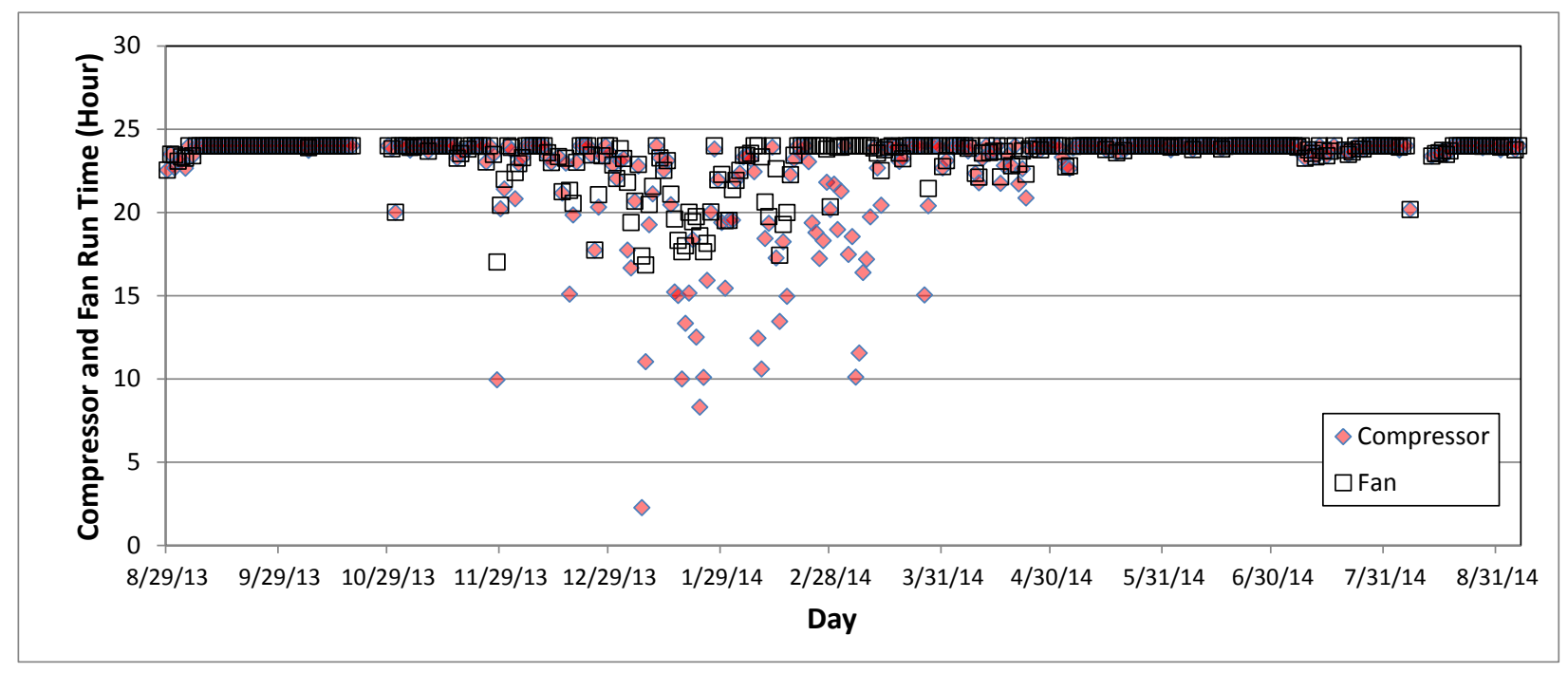

Figure 8: Compressor and Fan Run Time for the Reference unit when the Unit is either in Cooling or Ventilation Mode (but not heating mode)

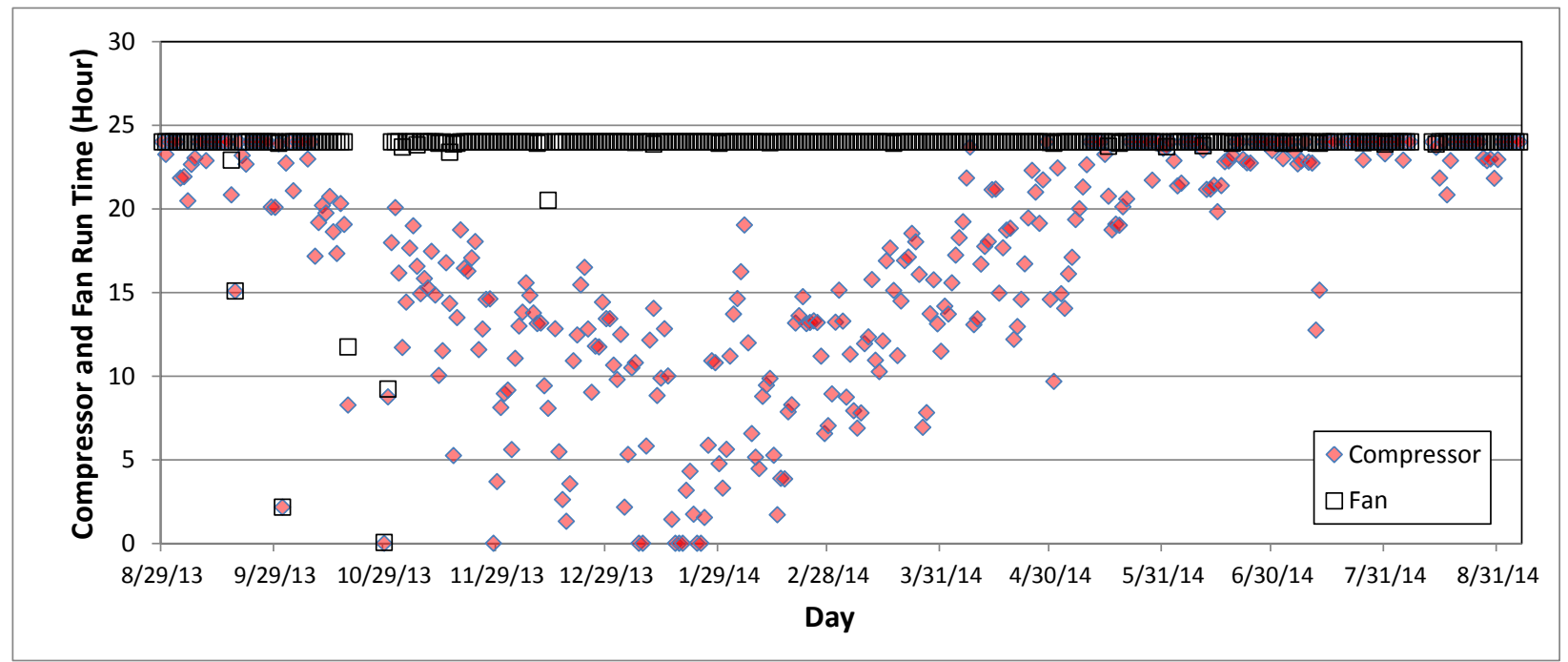

Figure 9: Compressor and Fan Run Time for the Rebel Unit when the Unit is in either Cooling or Ventilation Mode (but not heating mode)

Figure 10 compares the daily energy efficiency, expressed as energy efficiency ratio (EER), of the reference unit and the Rebel unit for the entire monitoring period. The results are missing for some days (e.g., between $10 / 19 / 2013$ and 10/29/2013) because at least one of the two units lost communication during that period. This figure shows that the daily EER varies between 5 and $12 \mathrm{Btu} / \mathrm{Wh}$ for the reference unit and between 7 and 15 Btu/Wh for the Rebel unit. 


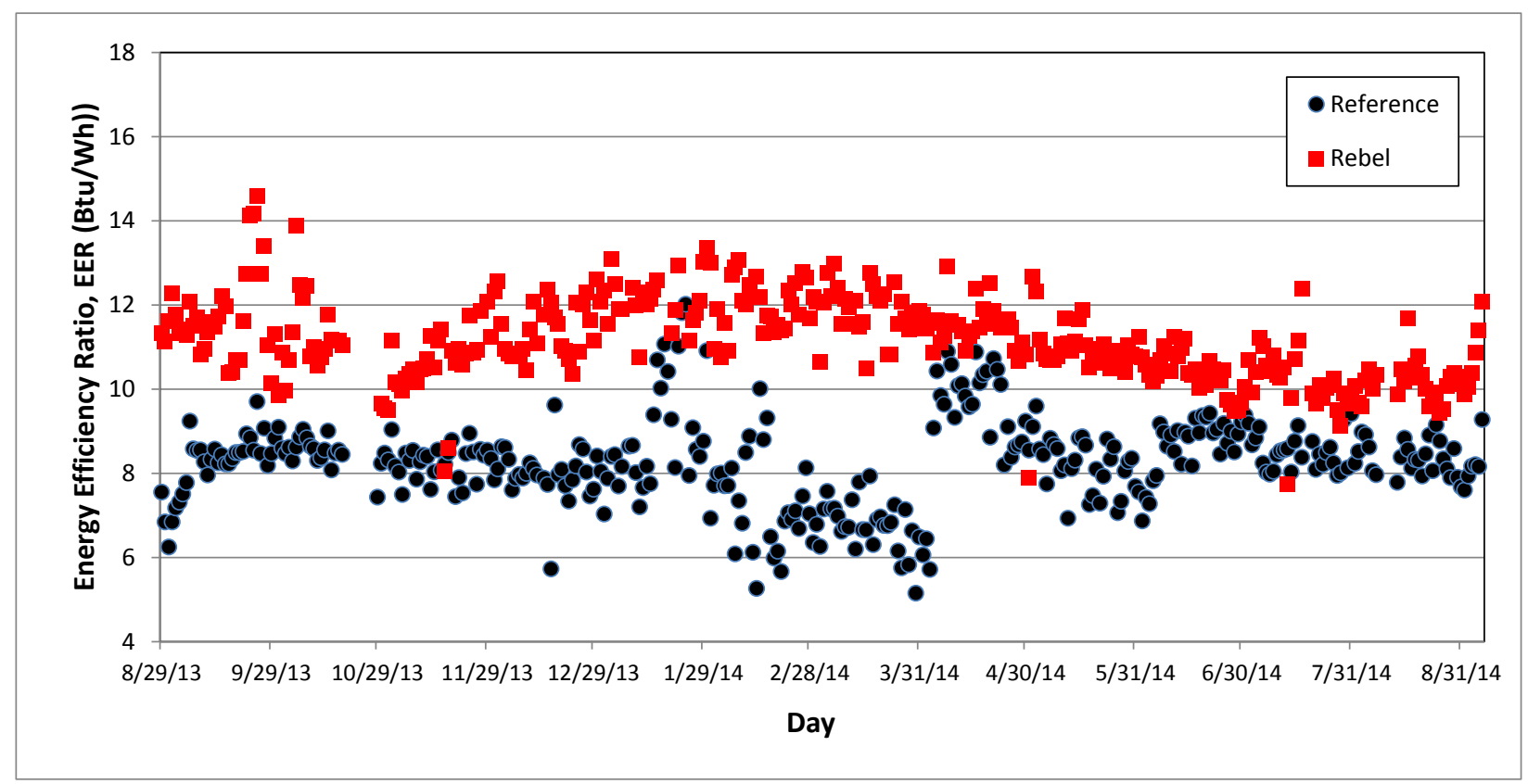

Figure 10: Comparison of Energy Efficiency Ratio of the Reference Unit and the Rebel Unit

Figure 11 compares the daily EER as a function of daily outdoor-air temperature for the standard unit and Rebel unit. In this figure, the daily average outdoor-air temperature is the average for those data records when the compressor was $\mathrm{ON}$. When the average outdoor-air temperature was lower than $55^{\circ} \mathrm{F}$, no data were available for the Rebel unit because that unit's compressor was not on and therefore EER could not be calculated. Figure 11 shows that in general, EER increased as the outdoor-air temperature decreased for Rebel units, which was expected. However, the relationship for the reference unit is not clear. 


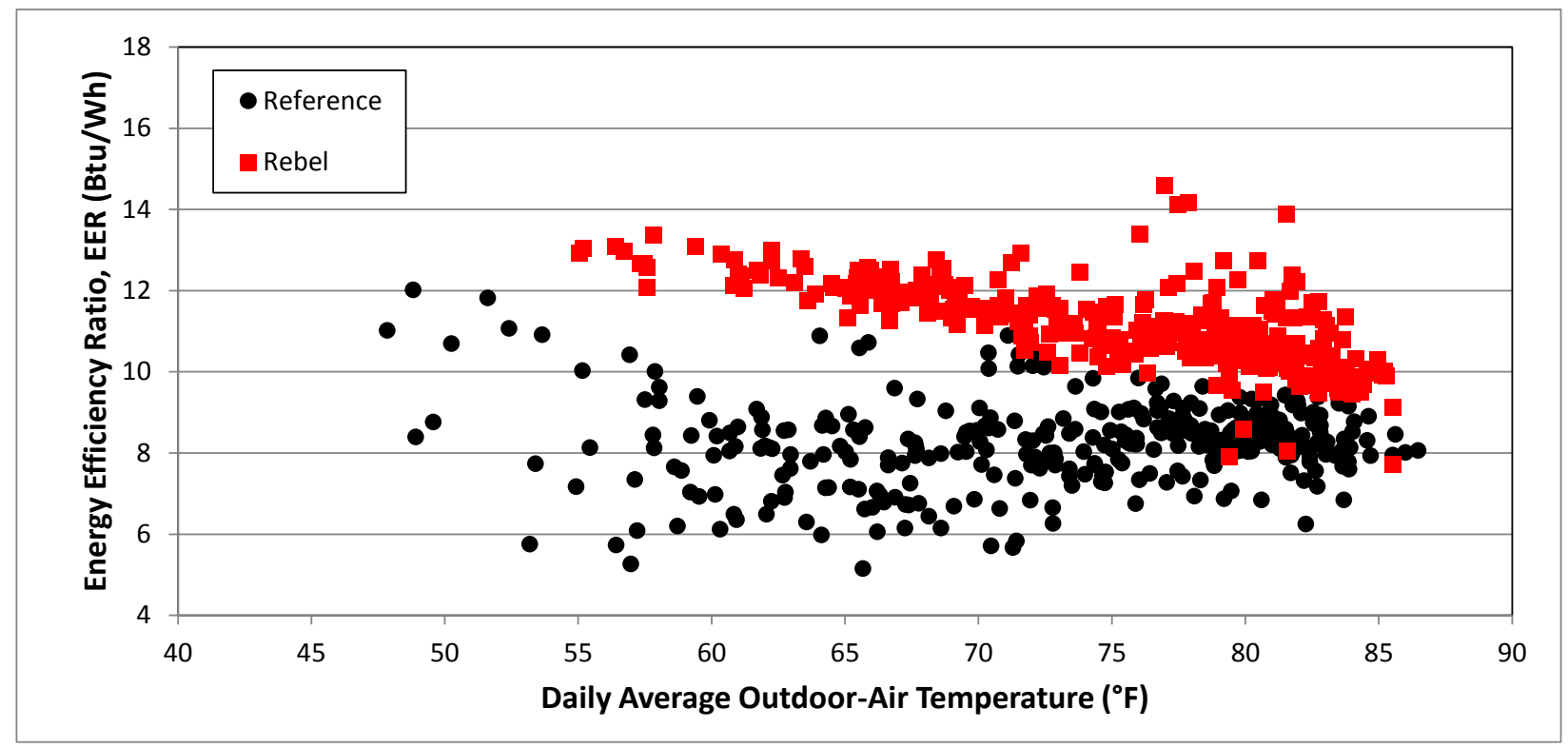

Figure 11: Comparison of Daily Energy Efficiency Ratio of the Reference Unit and the Rebel Unit as a Function of Daily Average Outdoor-air Temperature for the Monitoring Period

To compare the difference in daily efficiency (EER) between the two units, the ratio of EER of the Rebel and the reference units were calculated for all days and plotted as a function of the daily average outdoor-air temperature in Figure 12. The ratio of the EER for the two units ranged from 0.90 to 2.41. The Rebel unit had a higher daily EER than the reference unit for all but 3 days (i.e., 11/17/2013, 5/01/2014, and 7/13/2014), when the ratio of EER fell below 1.0. The EER ratio increased as the daily average outdoor-air temperature decreased. This means that RTUs with variable-speed compressors and variable-speed fans, like Rebel, had better part-load efficiencies than units that did not have variable-speed fans and use on/off controls for capacity modulation. 


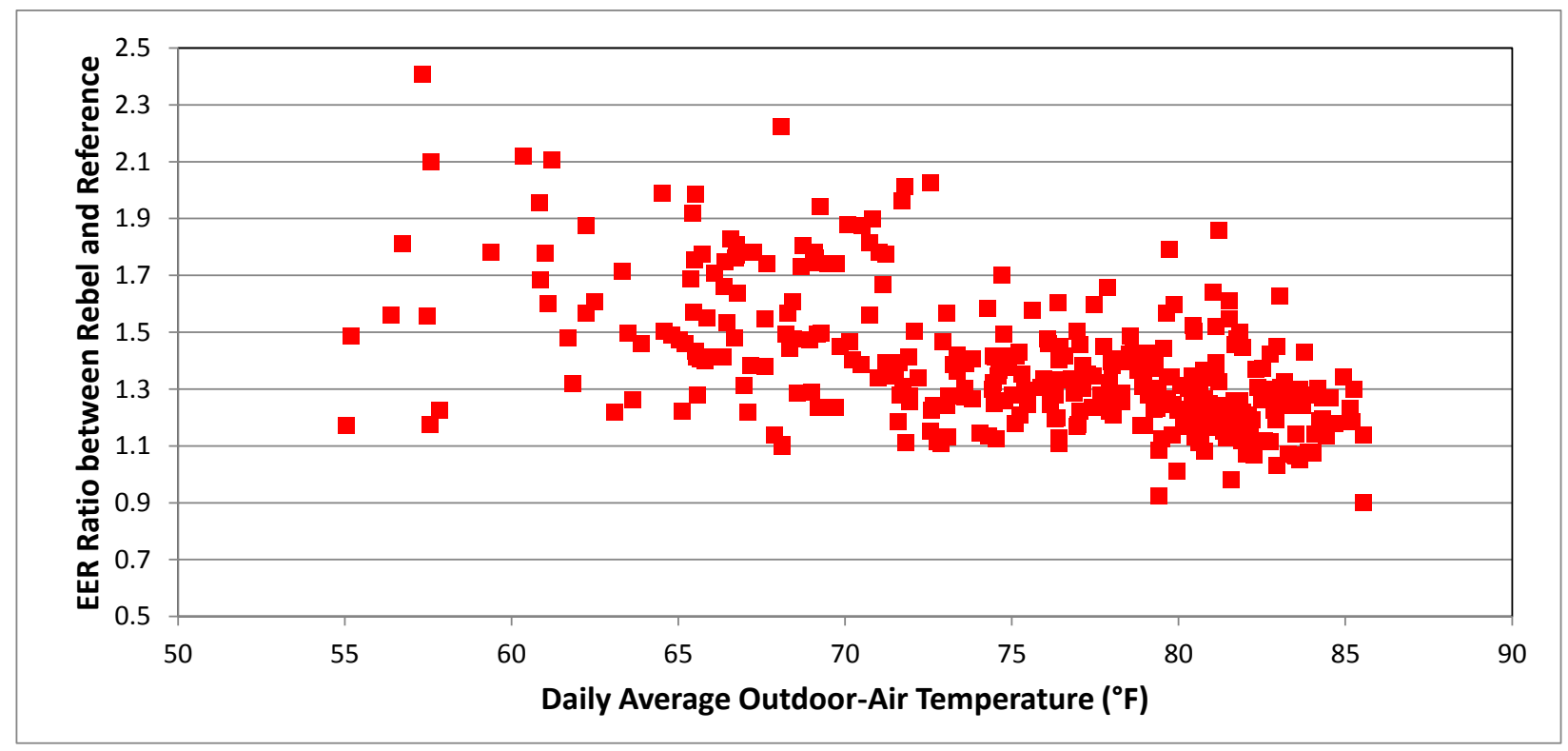

Figure 12: Ratio of Rebel EER and the Reference Unit as a Function of Daily Average Outdoor-air Temperature

The average of the EER ratio for all days in Figure 12 was approximately 1.38, which means that on average, the daily EER of the Rebel unit was 38\% higher than that of the reference unit.

In addition to daily EER, the seasonal cooling efficiency was also calculated using Equation 9. Table 3 shows the seasonal EER values computed over the entire monitoring period (the reference unit was from 7/28/2013 to 9/6/2014 and the Rebel unit was from 8/29/2013 to 9/6/2014). Over the 12-month period, the reference unit and the Rebel unit had seasonal EERs of 8.3 and 10.9, respectively. The Rebel unit's seasonal EER was about $31 \%$ higher than the reference unit. This result was slightly lower than the findings from our previous simulation work (Wang and Katipamula 2013), which predicted that in hot and humid climates, Rebel would consume about $40 \%$ less electricity than an RTU with a constant-speed supply fan and a single-stage mechanical cooling. The reasons for this difference were that the load that these units in the field were serving was different, while the units in the simulation served the same load. In addition, the reference unit in the field had a higher rated EER than the reference unit used in the simulation analysis. Also, as discussed previously (Figure 8 and Figure 9), both the reference unit and the Rebel unit ran in the cooling mode for a significant fraction of the time. Thus, the benefits of fan energy reduction in the ventilation mode did not exist. It is reasonable to anticipate that the Rebel unit will perform even better than the reference unit if the units operate more time in ventilation mode.

It needs to be noted that the meaning of seasonal EER and daily EER in this work are slightly different from those used in the performance rating standard for RTUs (AHRI 2007) in the following aspects: 1) the two units had higher external static pressure than the rating standard requirement; and 2) the efficiency calculated in this work included frequent mode changes and thus did not represent the steady-state efficiency used in the rating standard. 
Table 3: Comparison of Seasonal EER between Rebel and the Reference Unit

\begin{tabular}{|l|r|}
\hline RTU & Seasonal EER (Btu/Wh) \\
\hline Reference & 8.3 \\
\hline Rebel & 10.9 \\
\hline \multicolumn{2}{|c|}{ Seasonal EER improvement: $31 \%$} \\
\hline
\end{tabular}

\section{Annual Energy and Cost Savings}

The annual energy consumption for the Rebel unit was approximately 18,000 kWh, including 17,000 kWh in the cooling mode (total unit consumption) and $1,000 \mathrm{kWh}$ in the pure ventilation mode. If the site chose to install the standard reference unit instead of the Rebel, it would have consumed approximately $34,000 \mathrm{kWh}$ (considering the Rebel was approximately $30 \%$ more efficient than the standard reference unit in the cooling mode and $90 \%$ more efficient in the pure ventilation mode $-17,000 / 0.7+1,000 / 0.1$ ). The difference (savings) in energy consumption was approximately $16,000 \mathrm{kWh}$. The electricity rate that the site pays was approximately $\$ 0.10 / \mathrm{kWh}$. Therefore, the annual savings from installing a Rebel instead of the standard unit was roughly $\$ 1,600$. The incremental cost reported by the site for installing the Rebel was approximately $\$ 6,000$, which translated to roughly 3.8 years in simple payback. 


\section{Conclusions}

It was a challenge to find two units running in two different spaces that served similar cooling loads. Although two grocery stores with similar layouts were selected, the monitored data showed that they had noticeably different load profiles. Therefore, absolute energy savings between the two units could not be calculated. If the absolute savings measurement were desirable, then the existing RTU will have to be monitored for 1 year, followed by 1 year of monitoring of the Rebel unit after it replaces the existing RTU.

Other issues related to the installation of the Rebel unit included:

- The Rebel unit came with a different base footprint from the existing Lennox unit. Although a curb adapter was provided, it left the unit suspended over the front side of the base, and was ultimately supported by blocks.

- Although the new Rebel unit was considerably heavier than the unit it replaced, no roof reinforcement was needed.

The store that had the Rebel unit reported no comfort issues either positive or negative. The Rebel unit had a Micro Tech III controller, which was not compatible with the existing Emerson E2 BX controller, or the Emerson Building Automation System (BAS). Emerson had an application for the Micro Tech II controller but not for Micro Tech III. Therefore, the store had to install an output board with a set of dry contacts to control the RTU indoor fan. They also had to add an interface to monitor the indoor fan "On/Off" status and the supply/return temperatures, but they could not control any cooling/heating/speed control functions. All operations were controlled directly by the Micro Tech III controller in the unit with input from the zone temperature sensor.

The start-up and commissioning of the Rebel was challenging because the local Daikin distributor who installed the unit had limited experience in installing these new units. In addition, the controller had many features with a large instruction/operation manual, which made it difficult to properly configure. It took the distributor a couple of trips to configure the unit correctly, but after it was configured, the unit, as well as its metering and monitoring system worked as expected. Over the last 12-month period, maintenance requirements for this unit were similar to the other units. Because the Rebel unit had a lot of variable-speed components and controls (compared to the reference unit with standard parts), the energy manager speculated that using a Rebel unit could lead to costly repairs if anything failed during its lifetime. Also, the energy manager speculated that the Rebel unit may not be cost effective in coastal environments, where the equipment does not usually make the expected life cycle because of corrosive (salt air) conditions.

As described previously, the field performance of the Rebel unit was compared with a reference RTU that had been installed for about 6 years. Both units had a rated cooling capacity of 7.5 tons. The reference RTU had a constant-speed supply fan and two-stage mechanical cooling. Based on the comparisons of performance between the two units, Rebel had $30 \%$ higher seasonal EER compared to the reference unit. If the site installed the standard reference unit instead of the Rebel, it would have consumed approximately 16,000 kWh more annually leading to additional energy costs of roughly $\$ 1,600$. The incremental cost reported by the site for installing the Rebel was approximately $\$ 6,000$, which translated to roughly 3.8 years in simple payback. 


\section{References}

AHRI. 2007. ANSI/AHRI Standard 340/360-2007: Performance rating of commercial and industrial unitary airconditioning and heat pump equipment. Air-Conditioning, Heating, and Refrigeration Institute, Arlington, VA.

ASHRAE. 2010. ASHRAE Standard 90.1-2010: Energy Standard for Buildings Except Low-Rise Residential Buildings. American Society of Heating, Refrigerating and Air-Conditioning Engineers Inc. Atlanta, GA.

Daikin. 2013. Rebel commercial rooftop systems. Retrieved in January 2013 from http://www.daikinapplied.com/rooftop-rebel.php

DOE. 2013. High performance rooftop unit. Retrieved in January, 2013 from http://www1.eere.energy.gov/buildings/commercial/bba_rtu_spec.html

EIA (Energy Information Administration). 2003. Commercial Building Energy Consumption Survey. Retrieved in September 2013 from http://www.eia.gov/consumption/commercial/data/2003/.

Wang W, and S Katipamula. 2013. Part-Load Performance Characterization and Energy Savings Potential of the RTU Challenge Unit: Daikin Rebel. PNNL-22720, Pacific Northwest National Laboratory, Richland, WA.

Wang W, S Katipamula, H Ngo, RM Underhill, DJ Taasevigen, and RG Lutes. 2013. Advanced Rooftop Control (ARC) Retrofit: Field-Test Results. PNNL-22656, Pacific Northwest National Laboratory, Richland, WA. 


\section{u.s. Department of Energy Efficiency \& ENERCY Renewable Energy}

Add program specific contact information here Add program email address here 